\title{
El juez Josep Maria Bertran de Quintana (1884-1960): compromiso político y cementerios clandestinos*
}

\author{
Oriol Dueñas \\ Centre d'Estudis Històrics Internacionals de la UB (CEHI) ${ }^{1}$ \\ Queralt Solé \\ Universitat de Barcelona ${ }^{2}$
}

RESUMEN: El presente artículo forma parte de un trabajo más extenso centrado en el estudio biográfico de Josep Maria Bertran de Quintana (1884-1960), destacado político catalán durante la Segunda República, con un papel relevante en la proclamación de la República Catalana y, posteriormente, como regidor en el Ayuntamiento de Barcelona. Presidente del Comitè Català contra la Guerra y prolífico autor en los años 30, su implicación en las investigaciones de la violencia en la retaguardia de la República con el sumario llamado de los cementerios clandestinos durante la Guerra Civil le comportó adquirir, además, un importante perfil como juez

* Archivo del Colegio de Notaría de Barcelona (ACNB), Archivo Histórico de la Universidad de Barcelona (AHUB), Archivo Histórico Nacional (AHN), Arxiu Municipal Contemporani de Barcelona (AMCB), Archivo del Tribunal Superior de Justicia de Cataluña (ATSJC), Arxiu Nacional de Catalunya (ANC), Archivo Departamental de Tarn (ADT), Archivo Departamental de Ariège (ADA), Archivo Histórico del Ministerio de Asuntos Exteriores (AHMAE), Centro Documental de la Memoria Histórica (CDMH), Arxiu Històric de Girona (AHG).

1 Este artículo forma parte del proyecto de investigación «El franquismo en Cataluña: institucionalización del Régimen y organización de la oposición (1938-1979) (2)», subvencionado por el Ministerio de Ciencia e Innovación, HAR2009-10979, vinculado al Grup de Recerca Consolidat de la Generalitat de Catalunya «Grup de Recerca i anàlisi del món actual (GRANMA)», GCR 2009-2013.

2 Este artículo forma parte del proyecto de investigación «El pasado bajo tierra: exhumaciones y políticas de la memoria en la España contemporánea en perspectiva transnacional y comparada», vinculado al Consejo Superior de Investigaciones Científicas y subvencionado por el Ministerio de Ciencia e Innovación, CSO2012-32709. 
preocupado por la aplicación de la ley hasta que, en 1938, le cesaron del cargo. Su participación política en la República le supuso el exilio a México y ser objeto de represión por parte del régimen franquista.

Palabras Clave: Josep Maria Bertran de Quintana; República Catalana; Justicia; Guerra civil; violencia; fosa común.

The judge Josep Maria Bertran de Quintana (1884-1960): political compromise and clandestine cemeteries

ABSTRACT: This article belongs to a lengthy piece of work focused on the biography of Josep Maria Bertran de Quintana (1884-1960). He was a distinguished Catalan politician during the Second Republic, with a relevant role in the Catalonian Republic proclamation and, later, as an alderman in the Barcelona's city council. President from the Catalan Committee against the War and prolific writer in the 30's, his involvement in the violence investigations in the rearguard of the Republic during the Spanish Civil War entails him to obtain, besides, an important role as a judge. He worried about law application until 1938, when he was dismissed from its position. His participation in the Republic forced him into exile to Mexico and be subjected to repression by the Franco regime.

KEY WORDS: Josep Maria Bertran de Quintana; Catalonian Republic; justice; Spanish Civil War; violence; common graves.

\section{LOS PRIMEROS AÑOS, JUVENTUD Y ASENTAMIENTO PROFESIONAL}

Josep Maria Bertran de Quintana nació en el municipio de Sant Gervasi de Cassoles $^{3}$, en el número 7 de la plaza Cardona, el 2 de enero de 1884 en el seno de una familia de tradición militar perteneciente a la alta burguesía de la sociedad catalana. Sus padres, Valentí Bertran i Feliu, teniente coronel de artillería del ejército, y Consol de Quintana i Sastre, tuvieron otros cuatro hijos: Anna, Miquel, Tomás y el propio Josep Maria ${ }^{4}$. La muerte de su madre, acaecida el 16 de enero de 1887, cuando Josep María contaba tan solo con 3 años ${ }^{5}$, marcó su infancia.

El que con los años se convertiría en juez y asumiría un papel relevante en el período de la Guerra Civil en Cataluña, estudió en el Colegio de Sant Agustí de Barcelona. El bachillerato lo cursó en Girona hasta el año 1897,

3 El antiguo municipio de Sant Gervasi de Cassoles fue anexionado a Barcelona en el año 1897. Se extendía por el antiguo distrito III de Barcelona, al noroeste de la ciudad, entre los municipios también independientes de Sarrià, les Corts, Gràcia y Horta.

4 La Vanguardia, 4 de febrero de 1887, 3.

5 Testamento de Valentí Bertran i Feliu, ACNB. 
fecha en que iniciaría la carrera de Derecho en la Universidad de Barcelona. Obtuvo el grado de licenciado en Derecho y la suficiencia universitaria en $1903^{6}$, a pesar de que no solicitó la obtención física del título hasta 1934, cuando finalmente le fue expedido por el Ministerio de Instrucción Pública y Bellas Artes 7 . Finalizados los estudios, se dedicó a los negocios y a diversas actividades a caballo entre Francia (Niza y París) y México, donde fue nombrado Secretario General de la Cámara de Comercio Española ${ }^{8}$. Algunos de sus viajes, los que realizó pasando por Estados Unidos, constan en los archivos de inmigración americanos, como los de vuelta a Barcelona en barco vía Nueva York ${ }^{9}$. El 10 de mayo de 1923 contrajo matrimonio con Valentina España de Digoine du Palais, cuya familia disponía de un amplio patrimonio, del que Bertran de Quintana se hizo cargo a partir de la boda. Esta responsabilidad, junto con los beneficios de los negocios que había realizado en México, le proporcionaron suficiente dinero para dedicarse a su verdadera vocación: la política.

\section{FUNDADOR DE ERC Y PARTÍCIPE EN LA DECLARACIÓN DE LA REPÚBLICA Catalana (1931)}

A partir de 1931, coincidiendo con los últimos meses de dictadura, Josep Maria Bertran de Quintana decidió dedicarse a la política activa. De ideas republicanas, progresistas y catalanistas, se relacionó con el Centro de Esquerra Republicana ${ }^{10}$, donde estableció primero contacto y más tarde amistad con Lluís Companys, del que más tarde será secretario. Fue miembro destacado en la fundación, en marzo de 1931, del partido Esquerra Republicana de Cata-

6 Expediente académico de Josep Maria Bertran de Quintana, AHUB.

7 Fondos Contemporáneo, AHN, Causa General. Legajo 1641, exp. 182.

8 "La Casa de América de Barcelona". La Vanguardia, 6 de febrero de 1927, 9.

9 Según los registros conservados por las autoridades de inmigración de los EE UU de la isla de Ellis, en Nueva York, Josep Maria Bertran de Quintana viajó desde Veracruz en dos ocasiones: el 20 de febrero de 1920 y el 7 de abril de 1923. El primer viaje que le lleva hasta Nueva York, con escala en La Habana, lo hace a bordo del buque P. Satrústegui. El segundo viaje será en el barco Montevideo. En las dos ocasiones su destino era Barcelona. Datos extraídos de http://www.ellisiland.org. Fundación de la isla de Ellis: Estatua de la Libertad [consultado el 30 de junio de 2011]

10 El Centre d'Esquerra Republicana de Barcelona se constituyó el 21 de mayo de 1931 en un local de la calle Duc de la Victòria. La primera junta directiva estuvo formada por Joan Lluhí i Vallescà como presidente; Amadeu Aragay como vicepresidente; Pau Bastida, como tesorero y los vocales Josep Bertran de Quintana, Joan Tauler y Dalmaci Costa. Edmund Iglesias fue nombrado secretario. El Pueblo, 22 de mayo de 1931, 3: «La organización de Esquerra Republicana de Catalunya». 
lunya $(E R C)^{11}$, del que sería candidato por Barcelona en las elecciones municipales que se debían celebrar el 12 de abril de 1931, y que darían la mayoría absoluta a la joven formación republicana, lo que significó el final de la monarquía y el advenimiento de la II República. El éxito de la joven formación se apoyó en dos aspectos: en primer lugar, en poder contar con un líder carismático como era Francesc Macià; y en segundo lugar, el acierto de plantear las elecciones no en clave municipal sino como un plebiscito entre monarquía o república.

La falta de candidatos y la proximidad de las elecciones llevaron a Bertran de Quintana a formar parte de la candidatura para el Ayuntamiento de Barcelona del distrito II en representación de ERC. En menos de un mes, el nuevo partido se daría a conocer disputando el liderazgo a Acció Catalana Republicana $^{12}$, que se presentaba a las elecciones como favorita a la victoria final. Bertran de Quintana hizo una muy buena campaña, logrando instalar la sede electoral del partido en un lugar estratégico de su barrio, como era el antiguo salón de billar del Café Condal en la calle Tapioles, esquina con la avenida del Paralelo ${ }^{13}$.

La victoria de ERC, en coalición con la Unió Socialista de Catalunya (USC), fue una sorpresa, obteniendo una clara mayoría en el consistorio al lograr 25 regidores $^{14}$. Las alianzas entre el Partit Radical, PSOE, UGT y Federales consiguieron ocho regidores; republicanos de otras formaciones, dos regidores, mientras que la Lliga Regionalista tan solo logró 12. La gran derrotada fue Acció Catalana, que no consiguió, a pesar de su prestigio, ningún regidor. La victoria de ERC en las elecciones municipales, sumada a la derrota del catalanismo conservador, sirvió para comenzar la hegemonía del joven partido republicano en toda Cataluña. En este contexto, hay que destacar los

11 Esquerra Republicana de Catalunya (ERC) nació de la unión entre el Partido Republicà de Lluís Companys y de Marcel·lí Domingo, del partido Estat Català de Francesc Macià y del grupo de la revista L'Opinió, dirigida, entre otros, por Joan Lluhí i Vallescà. Además de integrar estas corrientes políticas, la joven organización tuvo la habilidad de atraer diferentes núcleos republicanos o federalistas repartidos por toda la ciudad de Barcelona y el resto de poblaciones catalanas.

12 El partido Acció Catalana Republicana, llamado también «Partit Catalanista Republicà», fue creado en 1931 fruto de la unión entre Acció Catalana y Acció Republicana de Catalunya. Estaba integrado mayoritariamente por intelectuales, personalidades de profesiones liberales y clase media.

13 La Vanguardia, 5 de abril de 1931, 7.

14 Las elecciones se habían convocado según la ley municipal vigente de 1887. En ella se especificaba, entre otros puntos, que las listas de los candidatos eran abiertas, es decir, se votaba a personas y no a candidaturas de partidos o coaliciones políticas cerradas, además de contemplar la elección de mayorías y minorías según el sistema de mayorías. 
resultados de Bertran de Quintana en el distrito II de la ciudad de Barcelona, pues fue el candidato que consiguió atraer mayor número de votos $(4.367)^{15}$.

Confirmada la victoria de ERC y con la llegada de las noticias de los resultados del resto del país, empezaron los movimientos para derrocar la monarquía la noche del 13 al 14 de abril. En Barcelona, los principales líderes de las diferentes formaciones republicanas se reunieron de madrugada en el Hotel Colón, donde, aunque se optó por no llevar a cabo ningún tipo de plan concreto, sí se determinó no mantener el régimen monárquico responsable de la dictadura de Primo de Rivera. Sin embargo, al día siguiente se precipitaron los acontecimientos que acabarían con la proclamación, primero de la República y, después, de la República catalana.

Josep M. Bertran de Quintana fue testigo de excepción, ya que tuvo un papel destacado en todos los sucesos acaecidos. A primera hora de la mañana, se reunió con Lluís Companys, Nicolau Battestini y Amadeu Aragay, entre otros militantes, en la librería Ariel, cuyo propietario era Joan Casanelles, un destacado miembro del grupo del periódico de L'Opinió. En la reunión se decidió ir al Ayuntamiento de Barcelona para poner fin al régimen monárquico. Alrededor de la una de la tarde Bertran de Quintana, Aragay, Companys, Opisso y Battestini, llegaron a la casa consistorial. Desde su balcón, Lluís Companys proclamó la República española. ${ }^{16}$ Poco después, se presentó Francesc Macià para reunirse con los miembros del partido. Hacia las 14.15 horas, una vez finalizada la reunión, se dirigió al público que se había congregado en la plaza Sant Jaume, esta vez desde el balcón del palacio de la Diputación, y futura sede de la Generalitat de Cataluña, junto con Joan Casanovas. Pidió silencio a la masa de gente y proclamó la República Catalana dentro de una Federación de Repúblicas Ibéricas. Francesc Macià acababa de proclamar 1'Estat Català ${ }^{17}$. La redacción del discurso de proclamación del Estat Català estuvo a cargo, aparte del mismo Macià, de Bertran de Quintana, Ventura i

15 «Triunfaron en Barcelona 25 candidatos de la Izquierda Republicana, 12 de la Coalición Republicana-Socialista, 12 regionalistas y un republicano autónomo». Respecto al distrito II, La Vanguardia informaba de que se habían escogido cinco regidores, tres de ERC y dos de la Coalición Republicana Socialista. Sobre la jornada electoral se podía leer: «En las 52 secciones que componen este distrito, transcurrió la elección con absoluta normalidad. La afluencia de votantes fue numerosa, llegando a rebasar más del 65 por ciento de los electores que integran el censo. La jornada fue en extremo pacífica en todo el Pueblo Nuevo. La lucha por este distrito se desarrolló con toda normalidad, y lo mismo que en otros puntos, los electores formaban cola con las primeras horas de los distintos colegios. (...)». «Las elecciones municipales en Cataluña». La Vanguardia, 14 de abril de 1931, 10.

16 «Proclamo la República...» La Vanguardia, 14 de abril de 2011, 14. En este artículo se relatan los hechos del 14 de abril de 1931 a partir de las notas inéditas del periodista Joan Alavedra.

17 «La República se proclama en Barcelona». La Vanguardia, 15 de abril de 1931, 3. 
Gassol y Jaume Aiguader. Finalmente, después de esta jornada y de varias negociaciones con representantes de la joven II República llegados desde Madrid el 17 de abril de 1931, Francesc Macià decidió renunciar a la República catalana a cambio de una autonomía que recuperaba el nombre original e histórico de Generalitat, confiando en la promesa hecha por los representantes del gobierno provisional de que las futuras Cortes Constituyentes aprobarían un estatuto de autonomía para Cataluña.

\section{REGIDOR DEL AYUNTAMIENTO DE BARCELONA (1931-1934)}

Tras los sucesos que comportaron el cambio de régimen, poco a poco la normalidad se fue imponiendo en la ciudad de Barcelona así como en el resto de Cataluña. Las nuevas autoridades, una vez consolidadas, empezaron a trabajar, y el 16 de abril se eligieron tanto al alcalde, Jaume Aiguader ${ }^{18}$, como a los nuevos regidores del Ayuntamiento de Barcelona. Entre los regidores que prometieron el cargo destacaba Josep M. Bertran de Quintana como representante del distrito II por ERC. Ese mismo día ya se celebró la primera sesión del nuevo consistorio, en la que se expusieron las líneas de trabajo de la mayoría de ERC y de la minoría regionalista, así como la de la coalición Republicano-socialista. Por otro lado, se formaron las comisiones municipales y Josep M. Bertran de Quintana fue adscrito a las de Fomento ${ }^{19}$, de Responsabilidades en la Casa Municipal de la Misericordia y en el Asil de Nenes Desemparades $^{20}$.

18 Parece que la elección de Aiguader como alcalde fue una imposición de Francesc Macià. Todos esperaban que la elección recayese sobre Lluís Companys, con más experiencia en temas municipales, ya que había sido regidor en la etapa de la monarquía y, además, tenía un gran prestigio entre los ambientes de los rabassaires y algunos sectores del proletariado. Macià no desconfiaba de Companys, pero quería que el Ayuntamiento de Barcelona, de gran poder político, estuviese liderado por una persona de su máxima confianza, cualidad que cumplía Aiguader, pues formaba parte, como el propio Macià, del sector de Estat Català. ALQUEZAR, 1986: 29.

19 Las principales responsabilidades de la Comissió de Foment eran la instalación y reforma de los servicios relativos al mapa de la ciudad, apertura y alineación de calles y plazas, obras de urbanización, parques y jardines, ornamentación, reordenamiento de conducción de aguas, iluminación de la vía pública y dependencias municipales, alcantarillado y canalización de todo tipo de tranvías, rotulaciones y numeración de calles y plazas, monumentos públicos, instalaciones industriales, obras particulares y bomberos. Actes del Ple Municipal (del 20 de noviembre de 1930 al 24 de abril de 1931).Arxiu Municipal Contemporani de Barcelona (AMCB).

20 «La primera sesión del Consistorio republicano» La Vanguardia, 17 de abril de 1931, 7. Además de formar parte de estas comisiones municipales, también fue escogido como suplente de la Conferencia Hidrográfica de los Pirineos Orientales y del Hospital de Sant Pau 
En esos momentos, la situación económica del Ayuntamiento de Barcelona era precaria debido a la corrupción, a los excesos realizados durante la dictadura de Primo de Rivera (1923-1930) y a las deudas acumuladas por la Exposición Universal del año 1929, a lo que había que añadir la crisis económica mundial provocada por el crack bursátil de ese mismo año. Por otra parte, la Generalitat provisional de Cataluña no pudo disponer de recursos propios ni de competencias en los ámbitos de la política municipal para poder ayudar a los ayuntamientos catalanes hasta el 9 de septiembre de 1932, cuando las Cortes Españolas republicanas aprobaron el Estatut de Autonomía de Cataluña.

De esta forma, la política municipal barcelonesa de los años 1931 a 1934 estuvo claramente marcada por la falta de recursos económicos, las huelgas sectoriales, los conflictos vecinales y los enfrentamientos que se produjeron dentro de ERC, muchos de los cuales se produjeron a causa de la falta de experiencia política de sus miembros ${ }^{21}$. Estas disputas motivaron que la joven formación sufriera diversas crisis que acabarían provocaron su escisión en septiembre de 1933 con el nacimiento del Partit Nacionalista Republicà d'Esquerra (PNRE).

Fue, de hecho, el propio Bertran de Quintana uno de los responsables que provocaría una de las mayores crisis dentro del seno de ERC. Su falta de experiencia política le creó serios problemas, a pesar de que su trabajo en el Ayuntamiento en la etapa comprendida entre abril de 1931 y agosto de 1933 fue brillante. Además de mejorar los barrios de su distrito, como el denominado «Las Casas Baratas» o el de «El Pont de les Vaques», promovió la cultura $^{22} \mathrm{y}$, como miembro de la Comisión de Responsabilidades llevó a cabo una investigación exhaustiva de las irregularidades económicas que se habían detectado en los ejercicios anteriores, entre las que se encontraban las sucedidas en las colonias para niños del año $1926^{23}$.

de Barcelona. Posteriormente, a partir del 20 de abril de 1932, el Ayuntamiento de Barcelona reorganizó las comisiones para mejorar su eficacia. A partir de esa fecha, Bertran de Quintana quedó integrado en la Comisión de l'Eixample. La Humanitat, 21 de abril de 1932, 8.

21 El poco tiempo que tuvo la joven formación para preparar las elecciones, junto con la imposibilidad de llegar a un acuerdo electoral con Acció Catalana, obligó a Francesc Macià a buscar precipitadamente 33 nombres capaces de aspirar a una regiduría en un partido que no tenía una base amplia de candidatos. Las listas electorales, pues, estuvieron formadas por hombres de mucha valía y experiencia, pero también por otros con poca preparación o ninguna trayectoria política y que, al ser elegidos inesperadamente, hicieron del primer ayuntamiento republicano de Barcelona un foco permanente de preocupaciones y conflictos para ERC. CULLÀ i CLARÀ, 1977: 64.

22 En este sentido, destaca el importante trabajo cultural que bajo la denominación de Universidad Democrática buscaba dar cursos para que los obreros adquiriesen nociones sobre disciplinas científicas de carácter general. La Humanitat, 18 de junio de 1932, 4.

23 «L'afer de les 350.000 pessetes destinades a Colònies Escolars». La Humanitat, el 2 y 9 de febrero de 1932, denunciando las irregularidades cometidas por el anterior consistorio en la construcción de diversos hoteles en la plaza de España. 
En este período, Bertran de Quintana también participó activamente en mítines e impartió conferencias en diferentes centros republicanos del territorio catalán, extendiendo así el ideario de ERC. Por otro lado, escribió artículos para L'Opinió o El Diluvio, aunque los más importantes los publicaría en el periódico de ideario republicano y portavoz de su partido La Humanitat, con el que colaboró intensamente hasta el agosto de 1933, fecha en la que se inició su distanciamiento con ERC.

En La Humanitat escribió artículos de elogio a las figuras de Lluís Companys $\mathrm{y}$, especialmente, de Francesc Macià, los más destacados políticos de ERC, además de otros muchos defendiendo los ideales que conformaban su personalidad e ideario político, como eran la defensa de la República, la Autonomía de Cataluña, los partidos de izquierdas y, sobre todo, su antibelicismo. Aunque fue su ostensible laicismo el que le puso en apuros en más de una ocasión, como el incidente ocurrido con un grupo de católicos hostiles a sus tesis después de una conferencia en Sant Vicenç dels Horts. ${ }^{24}$

A partir del año 1932, además de dedicarse a la política y a escribir artículos, promovió intensamente el Comitè Català contra la Guerra, del cual sería presidente y cuya sede se encontraba en el Ateneu Enciclopèdic Popular en la calle del Carme, número 30 de Barcelona. Este comité fue la delegación catalana del Comité Mundial de Lucha contra la Guerra Imperialista, presidido por los escritores franceses Romain Rolland y Henri Barbusse ${ }^{25}$. Durante este período, Bertran se volcó en explicar a través del comité los peligros de la guerra transmitiendo los valores y ventajas del pacifismo a los ciudadanos de Cataluña. Para poder transmitir su ideario, Bertran de Quintana contó con la colaboración de destacadas personalidades políticas como Andreu Nin, Àngel Pestaña, Jaume Miravitlles o Jordi Arquer, quienes a parte de conferencias en pro de la paz, también publicaron varios artículos en la revista ; Guerra a la Guerra! ${ }^{26}$.

24 «Una conferència de Bertran de Quintana a Sant Vicenç dels Horts.» La Humanitat, 17 de mayo de 1932, pág. 8 .

${ }_{25} \mathrm{La}$ iniciativa de este movimiento pacifista estuvo liderada por estos dos escritores además de otras personalidades importantes del mundo académico europeo, como Albert Einstein. El 27 de mayo de 1932, se publicó en el diario L'Humanité un manifiesto para convocar un congreso contra la guerra que, después de diversas negativas por parte de capitales como Londres o Ginebra, se celebró finalmente en Amsterdam los días 27 y 28 de agosto de 1932. En él nacería el Comité Mundial de Lucha Contra la Guerra Imperialista, muy influenciado por el Partido Comunista de Francia y la Internacional Comunista. Ambos grupos desempeñaron un papel destacado en la organización de la institución en contra de la guerra y del fascismo.

26 De esta revista fue el director el propio Bertran de Quintana, siendo la sede de la redacción y administración la calle Vía Laietana, número 56, domicilio particular del propio Bertran. En AISA PÀMPOLS, 2000:177. 
Ese mismo año entró a formar parte de la logia masónica La Lealtad, una de las más antiguas y destacadas de Cataluña. Los masones eran grandes defensores de la paz, aunque los franceses y alemanes tuvieran como primordial objetivo la patria. Resulta difícil sopesar la influencia de la masonería en el pacifismo de Bertran, pero es destacable el hecho de que en marzo de 1932 la Gran Logia Española, en la que estaban auspiciadas muchas de las catalanas, se adhirió a la campaña impulsada por la Segunda Internacional contra la guerra animando a todas las logias a intensificar su lucha por la paz.

Las muy diversas actividades de aquellos años y el prestigio político que fue adquiriendo Bertran de Quintana desde 1931 no dejaron indiferente a uno de los órganos satíricos del momento, el semanario barcelonés El Be Negre ${ }^{27}$. Esta publicación se dedicaba a parodiar a escritores y personas vinculadas con el grupo L'Opinió, sin olvidar a clérigos, españolistas, miembros del Estat Català y de la FAI, a la que condenaban por su violencia. En concreto, a Bertran de Quintana El Be Negre le dedicó diversos artículos con críticas y comentarios sarcásticos desmedidos sobre su pobre conocimiento de la lengua catalana ${ }^{28}$. Según el semanario, Bertran había empezado a hablar y a escribir en catalán a partir del 14 de abril de 1931 y por esta razón le llamaban «el regidor mexicano». Las constantes críticas que recibió provocaron más de un enfrentamiento entre su persona y la publicación, llegando incluso a los tribunales. Pero a pesar de los enfrentamientos, el semanario no dejó de publicar corrosivos artículos contra Bertran de Quintana, llegando a satirizar su lucha contra la guerra:

El señor Bertran de Quintana, en la cruenta guerra que tiene declarada a la guerra, ha dado una conferencia contra la guerra (no contra la guerra a la guerra, sino simplemente contra la guerra, o sea a favor de la guerra contra la guerra) en la Associació de Joves Cristians. Parece que los argumentos utilizados son de orden más

27 El Be Negre fue un semanario satírico barcelonés que funcionó entre 1931 y 1936. Editado por Màrius Gifreda, fue dirigido por Josep Maria Planas hasta el principio de la Guerra Civil, cuando los elementos de la FAI lo clausuraron e hicieron desaparecer a su director. Las principales temáticas que abordaban eran literarias, políticas, religiosas, de espectáculos..., siempre polémicas y de gran actualidad.

28 Las críticas por su «pobre catalán» también eran objeto de análisis en otras publicaciones como El Mirador. Este semanario, fundado en el año 1929 por el abogado y político Amadeu Hurtado, de temática literaria, artística y política, contaba con una sección de aire sarcástico titulada «El mirador indiscret», en la que el 15 de junio de 1933 apareció un artículo criticando el defectuoso catalán de Bertran de Quintana de la siguiente manera: «El ilustre y aún más ilustrado regidor señor Bertran de Quintana dio la semana pasada en l'Ateneu Enciclopèdic Popular una conferencia pública (...) Las causas de las guerra y la forma de evitarlas. En este acto oratorio (...) pudimos constatar una vez más la forma desgraciada de hablar catalán. Las faltas de ortografía, de morfología, de léxico y de sintaxis fueron numerosas, persistentes y continuas. Puede que antes de hablar sobre la materia que sea, empiece por no atacar con tanto furor espartano a la gramática catalana. Y más aún si se es pacifista.» 
bien laico, los cuales, sumados a los argumentos cristianos que los Joves Cristians ya tenían, harán de los Joves Cristians unos de los enemigos más irreconciliables de la guerra, tan irreconciliables, como el mismo señor Bertran de Quintana ${ }^{29}$.

A partir del año 1933 la solidez de ERC en el Ayuntamiento de Barcelona se desmoronó por culpa de las disputas internas. La escisión que se produjo en el partido, con el nacimiento del PNRE, la muerte de un regidor y la expulsión de varios regidores acusados de corrupción, dejaron a ERC en minoría dentro del consistorio, situación que acabaría provocando su parálisis ${ }^{30}$. En este contexto fue donde Bertran de Quintana acabó alejándose de la formación. Primero, por la influencia que ejercía en el partido la organización separatista Estat Català y sus juventudes; segundo, porque la dirección del partido no lo tuvo en cuenta, como le habían prometido en un principio, como candidato en las elecciones al Congreso de los Diputados que se iban a celebrar en noviembre de 1933. La ruptura total se produjo cuando las juventudes del partido ${ }^{31}$ realizaron en el estadio de Montjuïc unos desfiles de estética militar con claros signos de admiración hacia los conceptos autoritarios de la disciplina, obediencia y veleidades de partido único. La asistencia a los desfiles del propio Macià, y otras personalidades de ERC, hicieron estallar una gran polémica en el Ayuntamiento de Barcelona en relación con el uso de infraestructuras municipales y la presencia de cargos electos en los actos. En los enfrentamientos, Bertran de Quintana se postuló en contra de su propio partido al declararse contrario a esas manifestaciones por parte de las Joventuts d'Esquerra i d'Estat Català. Ése fue el principio del fin de Bertran en ERC. En sus intervenciones en el pleno municipal declaró que ERC se encaminaba hacia el fascismo, afirmación que le supuso su inmediata expulsión del parti$\mathrm{do}^{32}$. El concejal Casanovas, portavoz de ERC en el ayuntamiento, fue el en-

29 «En Bertran de Quintana fa la guerra a la guerra.» El Be Negre, núm. 79, 20 de diciembre de 1932.

30 Para más información sobre las disputas de ERC dentro del Ayuntamiento de Barcelona véase ALQUEZAS, RAMON, 1986; CULLA, JOAN B., 1977.

31 Estos grupos se habían formado bajo la tutela del químico Baltà en Barcelona durante la dictadura de Primo de Rivera y en estos momentos estaban integrados en el partido al que pertenecía Macià, Estat Català. Aunque éste había pasado a formar parte de ERC, no cambiaron sus formas ideológicas de manifestarse, que quisieron imponer en ERC. Destacadas personas de este grupúsculo del nacionalismo independiente eran Josep Dencàs y los hermanos Badia. Véase VINYES i ROIG, 2010.

32 El debate del Ayuntamiento fue seguido con mucho interés por toda la prensa escrita. Los enfrentamientos políticos que había en ese momento y, muy especialmente, las luchas entre ERC y el sector escindido de L'Opinió, provocaron que cada medio de comunicación aprovechase para dar la versión de los hechos según sus intereses. La Humanitat titulaba así la noticia: «La Liga, radicales y amigos del sr. Lluhí, hicieron aprobar, después de un largo debate, una proposición de censura por la fiesta del domingo pasado en el Estadio de Montjuïc.» La Humanitat, 28 de octubre de 1933. 
cargado de dejar públicamente fuera del partido a Bertran de Quintana: «Aquí en el Consistorio sólo he hablado yo. Lamento haber de declarar que desde este momento, el señor Bertran de Quintana queda fuera de la minoría (de ERC) salvo si la dirección del Partido toma otras medidas». El hasta entonces regidor Bertran de Quintana mantuvo su opinión, a pesar de la contundencia del portavoz, e incluso declaró: «No me sorprende la expulsión de ERC y, además, ya la esperaba, pues con ella no se hacía más que aumentar una injusticia a las muchas que ya se habían hecho por parte de los dirigentes de ERC contra mi persona ${ }^{33}$. Bertran prefería dejar el partido antes que traicionar sus ideales, demostrando así su fuerte personalidad, sus ideas pacifistas y democráticas, anteponiéndolas al partido. Él mismo presentó su baja en el partido, así como la del Centro d'ERC de la calle de la França Xica, en el barrio del Poble Sec de Barcelona, del que era presidente ${ }^{34}$.

El caso de la disputa de Bertran de Quintana y su expulsión del partido se trasladó a los medios de comunicación y fue aprovechada por otras organizaciones políticas. El semanario $\mathrm{El} \mathrm{Be} \mathrm{Negre} \mathrm{volvió} \mathrm{a} \mathrm{fijarse} \mathrm{de} \mathrm{nuevo} \mathrm{en} \mathrm{su}$ persona y en un artículo titulado «En Esquerra no quieren pacifistas» se burlaba de la situación ${ }^{35}$. Así mismo, La Lliga Catalana (antigua Liga Regionalista), también aprovechó la figura de Bertran para desacreditar a ERC, su máximo contrincante en las elecciones generales que tenían que celebrarse el 19 de noviembre de 1933. Por su parte, el diario La Segarra ${ }^{36}$, de la Conca de Barberà y portavoz de la Lliga en la comarca, publicaba: «El Sr. Bertran de Quintana, regidor de l'Ajuntament de Barcelona i president del Comitè contra la guerra, s'ha separat d'Esquerra Republicana perquè segons diu, amb el feixisme dels escamots, són ells qui la preparen».

Aislado completamente de ERC en el Ayuntamiento, se dedicó a trabajar en total soledad en su distrito hasta las elecciones municipales del 14 de enero de 1934. A pesar de su aislamiento, Bertran de Quintana no dejó de participar y de hacer oposición en la vida municipal barcelonesa. En la sesión del 11 de noviembre de 1933, y ante la propuesta de levantar un monumento a los catalanes voluntarios caídos en la Gran Guerra, Bertran presentó una proposición defendiendo su ideario pacifista de no erigir ningún monumento. Tal como publicó La Humanitat, lo que había de ser un debate pacifista, acabó en una

33 «La cesión del Estadio de Montjuich» La Vanguardia, 28 de octubre de 1933, pág. 8.

34 En la nota de prensa aparecida en el diario L'Opinió el 11 de noviembre de 1933 se hablaba de que las causas que provocaron su separación habían sido los escándalos municipales y la actuación de los grupos de jóvenes de ERC.

35 El Be Negre, núm. 124, 1 de noviembre de 1933. En este mismo número aparecía una viñeta en la que un hombre le preguntaba a otro: ¿¿Por qué han expulsado al pobre Bertran? Porque de tan pacifista que era, les hacía la guerra».

36 La Segarra, 18 de noviembre de 1933, 2. 
especie de torneo de oratoria. ${ }^{37}$ Finalmente, la propuesta de Bertran fue rechazada. Este suceso fue el último enfrentamiento entre ERC y Bertran de Quintana. A partir de ese momento, Josep M. Bertran dejó el ejercicio de la política y se dedicó a presentar por toda Catalunya el Comitè Català contra la Guerra. Paradójicamente, y a pesar de su odio a la guerra, no sería hasta el inicio de la Guerra Civil que su persona volvería a ser noticia.

\section{LA GUERRA CIVIL: EL JUEZ DE LOS CEMENTERIOS CLANDESTINOS}

Hasta el estallido de la Guerra Civil, Bertran estuvo vinculado al Partit Sindicalista de Ángel Pestaña ${ }^{38}$. Empezó con diversas colaboraciones y consta su participación en un acto público realizado en septiembre de 1935. Lo que parece claro es que la relación entre Bertran y Pestaña nació de las relaciones establecidas alrededor del Comitè Català contra la Guerra. A partir de 1936, encontramos a Bertran participando activamente en mítines y conferencias del Partit Sindicalista, acentuadas con el estallido de la Guerra Civil y durante los primeros meses del conflicto ${ }^{39}$.

La rebelión militar se gestó justo cuando se proclamó la victoria electoral del Front d'Esquerres en Catalunya y del Frente Popular en España en febrero de 1936. El Ejército español junto con carlistas, falangistas y grupos de extrema derecha prepararon el golpe militar para llevarlo a cabo entre los días 17 y 19 de julio. A nadie le extrañó el levantamiento, lo que no esperaba el Ejército era el fracaso en algo que debía ser inmediato: la caída de la República. El levantamiento fracasó y España quedó dividida entre los defensores de la legalidad y la República (entre ellos Catalunya) y las zonas territoriales

37 La Humanitat, 11 de noviembre de 1933, 7.

38 Un problema que la CNT tuvo que afrontar fueron las escisiones, especialmente las provocadas por la lucha entre los anarquistas puros y los empíricos o reformistas. Los segundos eran partidarios de establecer contacto con los políticos de la izquierda catalanista, mientras que los primeros no querían apostar por esta vía. De una de estas escisiones nació el «Partido Sindicalista», fundado por Ángel Pestaña, ex director del diario Solidaridad Obrera, en abril de 1934 en Barcelona, el cual tenía como objetivo principal la formación de un partido de trabajadores que participasen en la acción política. En realidad, fue un partido de poca importancia durante la Guerra Civil. MOLES, 2000: 218-219.

39 Entre las conferencias que realizó en nombre del Partido Sindicalista, debe destacarse la que protagonizó en Girona el 18 de septiembre de 1936 bajo el título «Un solo objetivo: vencer al fascismo. En el Partido Sindicalista. La conferencia de Bertran de Quintana.» L'Autonomista, 19 de septiembre de 1936, pág. 2. Bertran de Quintana también tuvo una destacada participación en el Congreso del Partido Sindicalista celebrado en Barcelona el 22 de mayo de 1937. Concretamente, fue el responsable de presentar un informe sobre Justicia, en aquellos momentos su principal ocupación. "Congreso del Partido Sindicalista.» La Vanguardia, 23 de mayo de 1937, 7. 
donde triunfó el golpe militar. De esta forma lo que empezó como un golpe de Estado acabó en Guerra Civil. España quedó dividida en dos zonas diferenciadas, la una bajo control del ejército insurrecto y la otra bajo control de la legalidad republicana. En ambas retaguardias se practicó una fuerte represión hacia todas aquellas personas o grupos de personas a las que se les consideraba traidores a la causa. En la zona republicana la represión se ejerció sobre todo entre los clérigos o personas cercanas a la iglesia, así como personas consideradas de derechas o conservadoras (especialmente propietarios industriales o agrícolas), los grupos políticos cercanos a éstos o hacia la falange y carlistas. La represión la llevaron a cabo individuos relacionados con el movimiento obrero que, con la primera confusión del levantamiento aprovecharon para ocupar la calle. Fue una represión cruenta en diversas zonas de Catalunya y en ningún momento tuvo el apoyo de las autoridades republicanas; es más, a diferencia de la retaguardia donde había triunfado el golpe, las autoridades republicanas intentaron por todos los medios impedir este tipo de represión ilegal, cosa que en la zona rebelde no solo no se intentó parar sino que, además, se consintió y se fomentó.

La Generalitat, intentó por todos los medios posibles, desde el mismo inicio de la guerra y la avalancha violenta, salvar vidas de personas en peligro de muerte, autoridades municipales y particulares de las diferentes poblaciones del país ${ }^{40}$. El mismo Josep Maria Bertran salvó la vida de su sobrino, Carlos Trias Bertran, quien consiguió llegar a Marsella gracias a la actuación de su tío ${ }^{41}$. Pero la Generalitat, a pesar de sus esfuerzos, no controló la situación de violencia desencadenada hasta mayo de 1937, cuando ya habían sido asesinadas un mínimo de 8.360 personas $^{42}$, cifra en la que se contabilizan a todas las víctimas, desde las juzgadas por un Tribunal Popular y condenados a la pena máxima hasta aquellas que conducidas hasta un lugar solitario, alejado de cualquier núcleo urbano, asesinadas y abandonados sus cuerpos o enterrados de forma clandestina en un fosa común. Pero incluso antes de recuperar el control del orden público el gobierno catalán había decidido investigar y perseguir los asesinatos de su propia retaguardia. El 22 de abril de 1937, el presi-

40 En la Generalitat de Catalunya destacaron en esta empresa els consellers Josep Maria Espanya y Ventura i Gassol, así como personalidades situadas en áreas administrativas diversas, como Jaume Miravitlles, Joan Casanovas -presidente del Parlament de Catalunya- o Pere Bosch Gimpera, rector de la Universitat de Barcelona y futuro Conseller de Justicia. El president de la Generalitat, Lluís Companys, procuró en todo momento que las personas en peligro pudiesen salir al extranjero a partir de la colaboración de consulados y de la falsificación de documentos.

41 Jorge Trías Sagnier. «En memoria de mi padre». La Vanguardia, 28 de febrero de 1995, pág. 18. Carlos Trias Bertran, Barcelona 1918 - 1969, fue un destacado político falangista que ocupó relevantes cargos en la administración franquista en Barcelona y Madrid. 42 SOLÉ I SABATÉ, VILLARROYA I FONT, 1:1989. 
dente del Tribunal de Casación de Cataluña, Josep Andreu i Abelló, apoyado por el entonces Consejero de Justicia, Joan Comorera (PSUC), creó por Orden un Juzgado Especial que debía investigar los excesos de los primeros meses de la guerra, y nombró para dirigirlo a tres magistrados: Josep Maria Bertran de Quintana ${ }^{43}$, Josep Vidal Letcha ${ }^{44}$ i Antonio Fernández Ros ${ }^{45}$. La Generalitat en aquella época tenía jurisdicción propia respecto a la Administración de Justicia, e inicialmente las investigaciones las ideó y lideró esta administración, pero a partir del mes de mayo de 1937 perdió competencias y el Gobierno republicano intentó controlar la administración catalana. En el nuevo contexto, el departamento de Justicia, ahora encabezado por el Dr. Pere Bosch Gimpera, no sólo mantuvo su autonomía respecto a la cuestión de las investigaciones alrededor de los asesinatos perpetrados en la retaguardia republicana, sino que también contó con el total apoyo del Gobierno central.

El hecho era significativo: para la supervivencia de la República era importante demostrar su integridad de actuación durante los primeros meses del conflicto, cuando en diversas zonas que se habían mantenido leales se perpetraron numerosos asesinatos de personas religiosas, consideradas de derechas o públicamente fieles a los sublevados ${ }^{46}$. El Gobierno republicano quería y debía mostrarse firme en la persecución de estos crímenes: era importante demostrar que la justicia era independiente de cualquier poder político y hacer ver a la comunidad internacional que la República no iba a permitir más muertes y persecuciones arbitrarias. De los tres magistrados, el que llevó a cabo la mayor parte del trabajo y le dedicó más tiempo fue Josep Maria Bertran de Quintana, que pronto obtuvo jurisdicción sobre todo el territorio catalán. Hasta ese momento Bertran, en septiembre de 1936, había sido designado letrado asesor de la oficina jurídica que la Generalitat abrió en Gerona ${ }^{47}$, teniendo como misión principal revisar los procesos penales y de carácter social

43 Josep Maria Bertran de Quintana (1884-1960), abogado, miembro de Esquerra Republicana de Catalunya (ERC), partido con el que fue regidor en el Ayuntamiento de Barcelona,

44 Josep Vidal Letcha, designado Magistrado de la Audiencia de Barcelona el 28 de abril de 1937 para la investigación de los cementerios clandestinos. Tuvo una destacada actuación respecto a los casos de Sant Martí de Centelles, Cadaqués, Port de la Selva, Orriols i Cantallops (todos ellos en Gerona).

45 Antonio Fernández Ros, designado en noviembre de 1937 Magistrado de la Audiencia de Barcelona, recibiendo el encargo de investigar los sucesos de la comarca de la Cerdanya (Lérida-Gerona). Desde entonces la familia empezó a recibir amenazas con el fin de asustarlo. El 6 de abril de 1938 fue destituido por abandono del servicio: había huido a Francia.

46 Véase JULIÁ DÍAZ, 2006.

47 La oficina estuvo integrada por Josep Carbó Comas, Fermí Belande i Ignasi Rodríguez Grahit, en representación de la CNT; Salvador Llounch Cels, Josep Grau Vidal i Josep Serrats, por la UGT. La Vanguardia, 13 de septiembre de 1936, 6; L'Autonomista, 10 de septiembre de 1936, 2. 
instruidos por los juzgados de la Audiencia de la ciudad, así como examinar las actividades contrarias a la República, la represión contra la usura y estafas cometidas, accidentes de trabajo, pago de salarios, etc. Resumiendo, se hizo cargo de sumarios relacionados con aspectos laborales y aspectos penales relacionados con la persecución de gente contraria a la República. Al cabo de tres meses, el 8 de diciembre de 1936, fue nombrado de forma interina, por orden del entonces conseller de Justicia Andreu Nin, Juez del Tribunal Popular Local Número 15 de Barcelona, consolidándose en su carrera judicial iniciada de hecho hacia muy poco tiempo ${ }^{48}$. Afianzamiento que sería definitivo cuando el 15 de junio de 1937 fue nombrado magistrado y Presidente del Tribunal Industrial de Barcelona ${ }^{49}$. Con este nombramiento se premiaba su labor, pero a la vez se pretendía aprovechar su experiencia en el mundo laboral como empresario y su etapa en Gerona como letrado asesor. El 22 de junio tomó posesión del nuevo cargo, después de realizar la oportuna promesa ${ }^{50}$. Pero a pesar del nuevo cargo, Bertran de Quintana tardaría en desarrollar las labores propias de su nuevo nombramiento, puesto que a pesar de tomar posesión, se le requirió desde el Govern de la Generalitat para un nuevo encargo: investigar los cementerios clandestinos aparecidos desde el inicio de la Guerra Civil.

Pronto empezó a indagar, siguiendo siempre una dinámica muy parecida de funcionamiento. Abordar el caso de los cementerios clandestinos era, inicialmente, sencillo: a partir de una denuncia o carta enviada al juez denunciando la desaparición de una persona, la perpetración de un asesinato o indicando la existencia de una fosa común, el juez iniciaba un sumario para dilucidar los hechos. Los denunciantes pretendían poder rescatar los restos de sus allegados y trasladarlos al cementerio. Las denuncias en forma de carta explicaban las circunstancias, aportaban el máximo de datos posible e incluso adjuntaban fotografías:

Yo Josefa Duaso, hija de Constantino Duaso y Rosa Ibáñez, certifico que el día 19 de abril se personaron en esta casa, calle Valencia ${ }^{\circ} 226$, Panadería, unos individuos que de cierto no los reconocería, se llevaron a mis padres y que hasta la fe-

48 Diari Oficial de la Generalitat de Catalunya (DOGC), núm. 346, 11 de diciembre de 1936, 949.

49 El Tribunal Industrial de Barcelona funcionó entre 1908 y 1938. La jurisdicción especial de trabajo se inició en España con la Ley de tribunales industriales de 1908 y, posteriormente, con el Real Decreto de 20 de octubre de 1908 en el que se creaban los tribunales industriales en las capitales de provincia. Su jurisdicción abarcaba únicamente el territorio donde se encontraban establecidos y estaban presididos por un juez de primera instancia. Se componía de jurados, patronos y obreros y tenia competencia en materia de contratos y accidentes laborales.

50 Nombramiento como presidente del Tribunal Industrial de Barcelona. Fondos Contemporáneos, AHN, Causa General, legajo 1641, exp. 182. 
cha no han comparecido. Sus señas son las siguientes: Constantino Duaso, natural de Morillo de Sierra, 45 años de edad, de oficio panadero, vestía traje gris rayado, calzado alpargatas, cabellos negros algo blanquinosos. Rosa Ibáñez, natural de Fraga, llevaba abrigo azul claro, zapatos negros, y en su muñeca de la mano derecha tenía dos cicatrices, 42 años de edad... ${ }^{51}$.

En otras ocasiones los denunciantes explicaban cómo se habían producido los hechos alrededor de la desaparición de sus familiares, relatos que, por otra, parte, son una buena fuente de información para conocer cómo actuaban las patrullas de control, principales protagonistas de los asesinatos:

Que el pasado 16 de marzo, habiéndose presentado en el domicilio mencionado, el de sus padres, dos individuos que ostentaban carnets y placas de Agentes de la Autoridad y una orden de detención para José Udina y Josefa Martorell, su esposa, padres del denunciante, y requeridos por aquellos supuestos agentes a prestar una declaración en la Comisaría General de Orden Público, se prestaron a ello, en vista de los documentos acreditativos de su personalidad, montaron al coche que llevaban, marchando de su domicilio sin que hasta la fecha, a pesar de la diligencias iniciales policíacas y particulares, se haya podido saber nada de su paradero ${ }^{52}$.

En cada uno de los sumarios instruidos en las diferentes poblaciones se tomaban declaraciones, se personaban en la fosa común las autoridades locales y tanto los forenses como el juez estaban presentes en las exhumaciones. En Sitges, por ejemplo, se levantó acta de la exhumación en el cementerio:

En la villa de Sitges a 5 de agosto de 1937, siendo las 18 horas y 35 minutos, el Sr. Don Bertrán de Quintana, Juez Especial, con asistencia del Infrascrito Secretario, y acompañados del Alcalde Presidente de esta villa don Francisco Richart Blanes y del Consejero de Sanidad, Cultura y Asistencia Social, don José Sánchez Guerrero [...] se constituye en el Cementerio Municipal, donde han asistido también previamente citados los sepultureros Luis Sabater Pascual y Antonio Mirabent Hill, con objeto de determinar el lugar del recinto donde existan depósitos clandestinos de cadáveres, y al efecto los dos sepultureros sin titubeos señalan el Parterre frente a los nichos 74 al 112 situado en la parte lateral izquierda entrando en donde en una extensión de 11 pasos de largo y 4 de ancho, aseguran se hallan enterrados clandestinamente 13 cadáveres sin ataúd. El Parterre del ángulo formado por la pared lateral de la derecha entrando y al fondo en donde en una extensión de diez pa-

51 “Denuncias por desaparecidos hechas durante la época roja”. Fondos Contemporáneos, AHN, Causa General, legajo 1638, exp. 61.

52 Esta carta se envió conjuntamente con diversas fotografías de la persona desaparecida e información con la dirección de la patrulla de control que había llevado a cabo la detención. "Denuncias por desaparecidos hechas durante la época roja". Fondos Contemporáneos, AHN, Causa General, legajo 1638, exp. 61. 
sos de largo por diez de ancho aseguran que hay enterrados siete cadáveres sin caja también clandestinamente ${ }^{53}$.

A partir de todas las denuncias recibidas, alentando a las autoridades municipales a colaborar, se empezaron, en medio de la guerra, las investigaciones y las exhumaciones de cadáveres. Éstas se realizaban con la presencia de forenses, que tomaban nota y certificaban todo lo que se debía resaltar para determinar la causa de la muerte y una posible identificación, para acto seguido proceder a ordenar la detención de los presuntos culpables. Eran interrogados por el juez, que incluso a veces realizaba un cara a cara con familiares de las víctimas y los presuntos culpables y un registro de sus casas para localizar pruebas, registros en los que el juez Bertran de Quintana siempre estuvo presente. Desde junio y hasta noviembre de 1937 se exhumaron 2.073 restos de fosas aparecidas en Molins de Llobregat (topónimo primitivo -t.p.- Molins de Rei); Roses de Llobregat (t.p. Sant Feliu de Llobregat); Montcada i Reixac; Les Corts; Prat de Llobregat; Sitges, Terrassa, Vilanova i la Geltrú, Barcelona, Olot, l'Escala.... y hasta en 14 municipios más ${ }^{54}$.

En las exhumaciones el forense realizaba una minuciosa descripción de cada uno de los cadáveres y se creaba una ficha donde se describían los objetos que se habían localizado junto a los restos. Además, en los casos en los que esto era posible, la ficha se complementaba con trozos de las telas de las ropas que aún se conservaban en los restos de la víctima. Así mismo, se permitía a las familias de las víctimas estar presentes en la apertura de la fosa.

Uno de los cadáveres exhumados en la fosa común de Montcada i Reixac era descrito de la siguiente forma: «Cadáver señalado $\mathrm{n}^{\mathrm{o}} 1$ : cadáver de sexo masculino de 25 a 30 años de edad, talla 1.70 metros, hábito normal, casi calvo, dentadura completa, estado de conservación esquelética, vistiendo pantalón de golf grueso, jersey de lana color granate, corbata color verde cuadros blanco (...)». Y respecto a la causa de la muerte, en este caso se concluía: «Cadáver $\mathrm{n}^{\circ} 1$ : presenta estallamiento de la bóveda craneal, interesando occipital, parietal y temporal, con probable agujero de entrada en el frontal y en el occipital producida por arma de fuego, que le ocasionó la muerte por hemorragia interna datando la misma de 12 a 13 meses $»^{55}$.

Desde la Generalitat de Catalunya y el Gobierno de la República se realizó una excelente tarea para dilucidar los asesinatos que se habían cometido en su

53 Sumario de la Causa 168-C, ATSJC. Juzgado de Instrucción núm. Especial.

${ }^{54}$ Los datos han sido elaborados a partir de la documentación conservada en el ATSJC y AHN. Debe resaltarse el hecho de que no ha sido posible hasta el momento localizar toda la documentación completa que se generó de los diversos sumarios realizados en este periodo. Es muy posible que la documentación se extraviase o se destruyese al final de la guerra.

55 Sumario de la Causa Criminal 168-H, ATSJC, Juzgado de Instrucción núm. Especial. 
propia retaguardia en los primeros meses del conflicto. Pero esta voluntad y ánimo de demostrar la inocencia por parte de los poderes públicos respecto a la responsabilidad sobre estos crímenes quedó frenada por cuestiones políticas. Las investigaciones, mantenidas sobre todo por el juez Josep Maria Bertran de Quintana de los tres que inicialmente habían sido designados para el caso, provocaron un constante goteo de detenciones de personas vinculadas a partidos de izquierdas y sindicatos, dando lugar a un creciente malestar entre éstos. La Generalitat, presionada por el PSUC y con el argumento de que las investigaciones estaban debilitando la causa republicana, tuvo que cerrar en diciembre de 1937 las indagaciones alrededor de los cementerios clandestinos. Un resumen del 18 de noviembre de 1937 especificaba que desde el mes de mayo habían sido procesadas 175 personas. De ellas, 32 estaban ausentes, 128 pasaron por prisión y 15 personas quedaron en libertad provisional después de ser detenidas ${ }^{56}$.

La labor del juez Bertran de Quintana no pasó desapercibida ni durante ni después de la guerra civil, unas veces para ser utilizada como prueba de los desmanes en la retaguardia de la República ${ }^{57}$ y otras para elogiarla. En este sentido, Francesc Cambó, líder de la Lliga Catalana afirmó:

Fa uns mesos, s'haurien castigat qui s'hagués atrevit a parlar-ne. Avui, els «cementiris clandestins» es descobreixen i els culpables són perseguits... i hom veu com hi és produïda una sensació d'horror a l'entorn dels fets que mesos enrere ningú s'atrevia a criticar i que eren sostinguts o protegits pels governants de Catalunya. És consolador, tanmateix, constatar que ni el crim, ni la insensatesa desbordada, ni l'extremisme epilèptic, poden durar molt de temps ${ }^{58}$.

56 Fondos Contemporáneos, AHN, Causa General. Pieza Quinta. Barcelona Justicia Roja, legajo 1635, exp 3.

57 Como por ejemplo en el periódico ABC (Edición Sevilla) el 29 de julio de 1937, pág. 7. «La triste ficción a que se dedican las autoridades de Barcelona.» «Las autoridades de Barcelona se dedican a una labor verdaderamente extraña: la del descubrimiento de los cementerios clandestinos, en los que, según ellas dicen, han sido enterradas miles de personas. Esas autoridades han nombrado un juez especial, que busca datos y pide planos de los lugares donde están enclavadas las siniestras necrópolis. También finge ese juez determinadas pesquisas para descubrir, según ha dicho a la prensa, a los autores de tantos y tantos asesinatos. Según parece cada pueblo de Cataluña tiene su cementerio clandestino. En los que rodean a Barcelona hay miles de cadáveres enterrados, y los de Tarrasa y Moncada son particularmente importantes [...] Lo curioso de todo esto es que las autoridades de la Generalidad aparecen muy sorprendidas de que existan esos cementerios clandestinos, como si por primera vez supieran que en Cataluña se habían cometido esos asesinatos. Las madres, esposas y hermanas de los desdichados que sufrieron la persecución marxista y que lloran sus pérdidas, no se sorprenderán, seguramente, como las autoridades y los consejeros de la Generalidad».

58 CAMBÓ, 1982: 152. 
Así mismo, el líder falangista catalán José María Fontana Tarrats también dedicó unas líneas de sus memorias a la tarea realizada por Bertran, destacando en este caso su valentía y los impedimentos que las autoridades republicanas le plantearon y que tuvo que afrontar:

Hacia el final de la guerra, y para quedar bien con los izquierdistas europeos, se nombró un juez especial -Bertrán de Quintana- antiguo diputado de esquerra por Gerona, para investigar y castigar sobre los llamados «Cementerios Clandestinos». Quintana no era mala persona, y tomó la cosa tan en serio, que llegó a empapelar a casi todos los dirigentes republicanos. Y durante la tramitación del proceso hubieron de asignarle un policía -era del Prat- para protegerle. El día que terminó la causa le dijeron que se la guardara, y tuvo que salir de España a uña de caballo, pues por poco lo eliminan a él ${ }^{59}$.

\section{REPRESIÓN Y EXILIO}

Interrumpido el sumario de los cementerios clandestinos, el juez Bertran de Quintana tomó posesión real del cargo que hasta el momento no había ocupado, el de presidente del Tribunal Industrial de Barcelona ${ }^{60}$. Era una forma de desaparecer de la vida pública y también de luchar contra la decisión de finiquitar las investigaciones de los crímenes perpetrados en la propia retaguardia por las autoridades políticas. No pudo, a pesar de todo, cumplir plenamente con sus obligaciones, puesto que las tensiones y el estrés acumulado sufrido como juez especial del sumario de los cementerios clandestinos le pasaron factura. Su salud se resintió y tuvo que ausentarse de sus obligaciones para recuperarse. El médico que lo visitó confirmó que el juez sufría una astenia generalizada - resultado probablemente del estrés y la fatiga acumulados-, así como una bronquitis crónica ${ }^{61}$. Una mala salud que ya no le abandonará y de la que se resentirá, sobre todo, en el exilio.

El 24 de enero de 1939, cuando las tropas franquistas ya habían cruzado el río Llobregat y se disponían a entrar a Barcelona, Josep Maria Bertran de Quintana y su esposa, Valentina, se dirigieron a la frontera con Francia, conscientes de que las nuevas autoridades no iban a perdonarle su implicación en la política republicana y de que si optaban por permanecer en el país, su vida

59 FONTANA TARRATS, 2005: 111

60 El retorno oficial al Tribunal Industrial se produjo el 18 de enero de 1938, momento en el que se cesó al juez accidental José García Amorós. Fondos Contemporáneos, AHN, Causa General, legajo 1641, exp. 182.

${ }^{61}$ El 31 de agosto de 1938 el Conseller de Justícia dictó una orden en la que se le concedía a Bertran de Quintana 30 días de licencia para que pudiese atender la recuperación de su salud. Fondos Contemporáneos, AHN, Causa General, legajo 1641, exp. 182. 
corría peligro. Cruzaron por Le Pertús el 29 de enero, iniciando así un largo exilio que perduraría hasta su muerte en México DF el 5 de febrero de 1960.

En Francia pasó por el pueblo de Saint-Sulpice (Midi-Pyrénées) y, posteriormente, se instaló unos días en Tolouse para tramitar con las autoridades del Consulado español un certificado de nacionalidad que debía ser firmado por el cónsul franquista. Ante esta exigencia, Bertran mostró su absoluto desacuerdo y expuso en una carta lo absurdo que resultaba la situación, con lo que demostraba una vez más su fuerte carácter y su compromiso con la República:

Il est facile de comprendre qu'en ma qualité de ex-citoyen républicain espagnol, alors qu'aujour'hui ma patrie est vexée par un régime d'oppression similaire à celui de l'Allemagne, je ne puisse pas me procurer ce document-là dans les conditions exigées (...) Est en contradiction avec l'esprit des Décrets parus aux «Journal Officiel» lequels établissent l'utilisation des étrangers sans nationalité et des étrangers bénéficiaires du droit d'asile. Donc, il est logique qu'il ne peut avoir deux poids et deux mesures différents dans cette utilisation. Si ce n'est pas une condition sine qua non, la presentation du dit certificat à plus forte raison, on ne devrait pas demander aux espagnols qui ont combattu Franco et qui se trouvent actuellment en France sous la protection des lois françaises, de leurs autorités, et, notamment, sous le bénéfice du droit d'asile ${ }^{62}$.

Ante la insistencia de Bertran, las autoridades francesas accedieron a concederle un permiso para poder transitar por el Estado francés. De vuelta en Saint Suplice, consiguió un trabajo como profesor que le permitió mantenerse en una situación estable hasta el estallido de la Segunda Guerra Mundial, cuando el matrimonio decidió que Valentina volviese a Barcelona, lo que se produjo el 30 de septiembre de 1940. Mientras tanto, Bertran de Quintana decidió permanecer en Francia, a pesar de la insistencia de su hermano, arquitecto afincado en México, para que se trasladase al país azteca. El 30 de junio de 1941 las autoridades francesas le detuvieron con el argumento de que debían concentrar a todos los extranjeros que por edad no podían integrar las Compañías de Trabajadores. ${ }^{63}$ Era tan solo un pretexto, ya que los verdaderos motivos de la detención eran políticos, tal y como las mismas autoridades reconocían en un documento fechado en febrero de 1942: «La Commission de Criblage l'avait retenu en raison du fait été le Secrétaire de M. Companys; President de la Généralité de Catalogne» ${ }^{64}$. A continuación, fue trasladado al

62 Fondo de la Prefectura de Tarn, ADT, cote 571, W 1516.

63 Orden promulgada por el ministro del Interior francés el 21 de abril de 1941, completada con la circular del mismo ministerio el 28 de noviembre 1941, en DREYFUSARMAND, 2000: 124.

${ }^{64}$ Fondo de la Prefectura de Tarn, ADT, cote 571, W 1516. 
campo de prisioneros de Vernet d'Ariège (Tarn) donde, con una salud muy precaria, estuvo hasta el 5 de diciembre. Después fue trasladado al campo de Noé (Haute-Garonne) ${ }^{65}$ y de éste, por complicaciones en su sistema respiratorio, al Sanatorio de La Guiche, donde se internaba a los enfermos de tuberculosis detectados en los campos de refugiados del sur de Francia ${ }^{66}$. Allí se quedó hasta el 9 de marzo de 1942, cuando con los permisos necesarios y auspiciado por la JARE (Junta de Auxilio a los Republicanos) pudo dirigirse a Marsella para embarcarse el 14 de abril en un barco francés que le llevó, primero a Casablanca y, posteriormente, en el Nyassa, a México, adonde llegó el 22 de mayo.

Josep Maria Bertran de Quintana se instaló en la capital, donde, delicado de salud y sin recursos económicos, fue apagándose. El 3 de junio de 1942 ingresó en el Sanatorio Español, en el que le detectaron una tuberculosis pulmonar y una ligera insuficiencia cardiaca ${ }^{67}$ y al salir, al cabo de unos meses, se instaló en casa de su hermano. Durante ese tiempo su máxima preocupación fue conseguir recursos económicos, dado que su deteriorado estado de salud le impedía encontrar trabajo. Solicitó ayuda a la JARE y también la tarjeta médico-farmacéutica en cinco ocasiones, hasta que a finales de 1942 recibió 695 pesos en diferentes subsidios ${ }^{68}$.

En los primeros meses de su permanencia en México la suerte no le acompañó. A pesar de que el 13 de febrero de 1943 recibía un nuevo subsidio de cien pesos, el día 23 fue atropellado, resultando gravemente herido y sufriendo una conmoción cerebral. Fue ingresado otra vez hasta el 2 de marzo y luego las secuelas le obligaron a mantenerse en cama durante una larga tempora$\mathrm{da}^{69}$. Finalmente su situación se estabilizó, con la obtención de un subsidio de 90 pesos mensuales a partir de mayo de 1943. Ya más recuperado, en 1948, tras conseguir la tarjeta de identificación que le permitía dedicarse a actividades remuneradas por parte de las autoridades mejicanas, pudo desplazarse a Francia para reencontrarse con su mujer, Valentina ${ }^{70}$. Juntos se trasladaron a México, donde permanecieron, sin que destaque actuación profesional ni política alguna, hasta la muerte de Bertran de Quintana el 5 de febrero de 1960. Valentina regresó a Barcelona, ciudad en la que, a pesar del perfil antifranquista de su marido, celebró en 1961 una misa en su honor en la Iglesia de Sant Ildefons ${ }^{71}$.

65 ADT, cote 5, W 282.

66 EGGERS, 2011: 14

67 Fondo Junta de Auxilio a los Republicanos Españoles (JARE), AHMAE, exp. 4203

68 La JARE ayudó a más de 2.000 personas solo en México, en MATEOS, 2009.

69 Fondo Junta de Auxilio a los Republicanos Españoles (JARE), AHMAE, exp. 4203

70 Fondo de la Prefectura de Tarn, ADT, cote 571, W 1516.

71 «Necrológicas. Primer aniversario del fallecimiento de don José M. Bertran de 
El juez del sumario de los cementerios clandestinos había marchado a Francia, primero, y posteriormente a México, había sufrido por sobrevivir, había tenido problemas de salud y había muerto en el exilio, pero su derrota personal no fue impedimento para que las autoridades franquistas le persiguiesen e intentasen expoliarlo económicamente. La justicia del Régimen aplicó a Bertran de Quintana las dos leyes que, a pesar de encontrarse fuera del país y según la nueva autoridad, se le podían aplicar: la ley para la represión de la masonería y del comunismo ${ }^{72}$ y la ley de Responsabilidades Políticas $^{73}$.

Bertran de Quintana había ingresado en la masonería el 5 de mayo de 1932 con el nombre simbólico de Agis en una logia histórica llamada Logia Leal$\operatorname{tad}^{74}$. Fundada en 1869, era la única logia catalana activa que estaba bajo los auspicios del Gran Oriente Español de Cataluña, aunque había pasado por dificultades ${ }^{75}$. Destacaba entre sus miembros Lluís Companys, que había entrado en 1922, y es posible que éste fuera el motivo por el que Bertran la escogiera. Pertenecer a la masonería no era extraño entre los políticos catalanes; de hecho, en el primer Parlamento catalán de 1932 había hasta nueve diputados masones y destacados políticos de diversos partidos eran masones. El juez Bertran, sin embargo, permaneció poco tiempo en la organización, puesto que en enero 1934 solicitó su salida, coincidiendo con su abandono del Ayuntamiento de Barcelona. Probablemente haya que buscar las causas en las tensiones de aquella época, ya que, aunque en principio las opiniones políticas o puntos de vista de los miembros no debían entorpecer el funcionamiento de las logias, a menudo era inevitable que se trasladaran a éstas. Según la documentación recopilada por el Tribunal para la Represión de la Masonería y el Comunismo, el antiguo juez era «orador adjunto» y llegó hasta el segundo grado dentro de su logia; es decir, estaba en las reuniones al lado izquierdo del Maestro, sintetizaba las discusiones y debía pronunciar los discursos ${ }^{76} \sin$ que destacase en otra actividad más allá de la asistencia a reuniones o formar parte de alguna comisión, como las de hacienda, beneficencia o justicia. Cuando se inició su persecución por masón, en noviembre de 1944, fue de rápida ejecución. En diciembre se solicitaban antecedentes y se iniciaba la «busca y captura de dicho encartado», y en enero de 1945 ya se le considera-

Quintana». La Vanguardia Española, pág. 33. Valentina España de Digoine du Palais murió el 25 de agosto de 1975, La Vanguardia Española, 26 de agosto de 1975, pág. 21.

${ }_{72}$ Ley Para la represión de la masonería y del comunismo, publicada en el BOE, núm.

29, del 2 de marzo de 1940.

73 Publicada en el BOE, núm. 44, del 13 de febrero de 1939.

${ }^{74}$ Sumario 1296-44 contra José Bertran de la Quintana por delito de masonería, CDMH, TERMC, 11453

75 SÁNCHEZ i FERRÉ, 1985; 1993.

76 Inventario de Fondos Masónicos de Cataluña y Baleares, Vol. 1 1993:14. 
ba en rebelión. Seguidamente, fue decretaba la prisión provisional y penado a reclusión menor con sus accesorias correspondientes ${ }^{77}$.

La otra ley represiva que le fue aplicada a Josep Maria Bertran de Quintana fue la de Responsabilidades Políticas ${ }^{78}$. Su expediente se abrió el 27 de febrero de 1940 y no se cerró hasta el 22 de mayo de 194779 , con el sobreseimiento del caso, tras aplicársele la absolución decretada el 27 de noviembre de 1945 para todos aquellos que no tuviesen bienes superiores a 25.000 pesetas. Sin embargo, la intención de penarle y expropiar su capital y propiedades queda bien patente en el expediente. Se observa cómo durante dos años se solicitaron datos económicos e informes varios a Falange, al cura de su parroquia, a los vecinos, creando de ese modo una fotografía muy completa del que había sido juez. Fue un trabajo concienzudo, dado que el perfil descrito por la Dirección General de Policía de Barcelona se ajusta del todo a la realidad, más allá de las valoraciones políticas que se formulan. De forma paralela, también se localizan todos los bienes de Bertran y los de su mujer:

No se le conocen bienes de fortuna a su nombre pero, en cuanto a su cónyuge, Valentina de España y de Digoine, que se halla en el extranjero, se tienen noticias de los siguientes bienes: Finca Rústica en Esplugas del Llobregat, de 1.025 metros cuadrados, sita frente a la calle denominada España: otra en la misma localidad de 1.813 metros cuadrados, que está situada en la esquina de las calles Molinés y Quintana. Procedente de la herencia de su padre las que siguen: una casa sita en la calle de Cipreret $\mathrm{n}^{\mathrm{o}} 2$ de Hospitalet de Llobregat, con adjuntas dependencias destinadas a cocheras, en un solar de un millón de palmos cuadrados; otra de planta y piso en la misma calle $\mathrm{n}^{\circ} 54$; otra de planta y piso en la citada calle, $\mathrm{n}^{\circ} 56$, otra de planta y piso en la referida calle $\mathrm{n}^{\circ} 58$, y dos más en los $\mathrm{n}^{\circ} 60$ y 62 . Además, un terreno entre las calles Centro y Saspresa. Censos dentro del término de Esplugas con una renta anual de 1.500 ptas. Capitalizadas en una de 40.000 ptas. Dos solares y una torre en Sitges.

En todas las informaciones recogidas sale a la luz que Bertran de Quintana había asumido la tarea de la persecución de los crímenes en la retaguardia de la República; sin embargo, esta circunstancia, en lugar de servirle como ate-

77 Sumario 1296-44 contra José Bertran de la Quintana por delito de masonería, CDMH, TERMC, 11453

78 Para una lectura más exhaustiva sobre el funcionamiento y la represión que se ejerció en Cataluña por parte del Tribunal de Responsabilidades Políticas puede consultarse: ÁLVARO DUEÑAS, 1990: 141-162; GARCÍA FONTANET, 2000; MIR, CORRETGÉ, FARRÉ, SAGUÉS, 1997; VÁZQUEZ OSUNA, 2005; VILANOVA i VILA-ABADAL, 1999. Para el funcionamiento de la ley, véase DIGÓN, quien realiza un detallado informe de la ley de Responsabilidades políticas y de su aplicación, centrándose en el caso de Joan Comorera: 2010.

79 Fondo del Tribunal de Responsabilidades Política, AGTSJC, exp. $n^{\circ} 2507$ (1940) Si no se especifica lo contrario, toda la información y las citas respecto al sumario instruido a Bertran de Quintana por la ley de Responsabilidades han sido extraídas de esta documentación. 
nuante, actuó en el sentido contrario. Así, desde el Ayuntamiento de Barcelona se informa de lo siguiente:

En julio de 1937 se le nombró juez del titulado (Juzgado Especial por asesinatos y cementerios clandestinos), procediendo al desentierro de un crecido número de cadáveres que yacían en diversos pozos, campos y zanjas de cementerios que simularon haber descubierto entonces, al objeto de imputarle los crímenes a la FAI, cuando en realidad era que los dirigentes rojos tenían perfecto conocimiento de ellos, puesto que todos les eran conocidos y muchos expresamente ordenados.

Y, desde Gerona, en un expediente de fronteras abierto en 1941, aún se hacía más énfasis en sus actividades como político republicano y juez, primero en Gerona y, posteriormente, en Barcelona:

Que dicho señor con anterioridad al G.M.N. era abogado y se cree tenía el bufete en Barcelona. Una vez estallado éste y en calidad de significado sindicalista, llegó a esta ciudad aproximadamente, organizando la Oficina Jurídica roja, representándola él en calidad de Presidente de la misma. Sujeto de instintos crueles, hizo que estuviese aterrorizada toda la Provincia. Déspota, perverso y canalla, generalmente iba siempre rodeado de algunos esbirros armados, de su calaña. (...) Ordenaba encarcelamientos a diestro y siniestro, así como exigencias considerables de entregas en metálico a cambio de dispensas y ciertos favores, ante los cuales no sentía el menor escrúpulo.

(...) En dicho cargo estuvo durante algunos meses, hasta que dejó de existir dicha organización jurídica, regresando entonces a Barcelona (...) hasta que pasado algún tiempo fue nombrado Juez especial del levantamiento de cadáveres, muchos de los cuales, es seguro, fueron urdidos los asesinatos por él y sus secuaces.

(...) Moral y materialmente persiguió a todas las personas que él consideraba fascistas. (...) En resumen, es un ser sumamente repulsivo y acreedor de los más duros cualificativos $(\ldots)\rangle^{80}$.

En la sentencia final de Josep Maria Bertran de Quintana se destacaba que había sido el juez de los cementerios clandestinos, pero no recogía ninguna de las acusaciones condenatorias emitidas por diversos organismos o personas. El entonces presidente del Tribunal en Barcelona, Manuel de la Prada y Sedas, ordenó la incoación del expediente y declaró a Bertran culpable de delitos graves:

José María Bertran de Quintana, de 55 años, sin bienes conocidos y la carga de esposa que tiene más de cuarenta mil pesetas en inmuebles, tiene antecedentes de izquierda, como militante de Izquierda Catalana, mantenida, y con cuya representación fue elegido Concejal, cargo que desempeñó hasta $1^{\circ}$ de Enero de 1934. En periodo rojo se afilió al partido sindicalista de Pestaña, siendo designado Juez especial de Ce-

80 Expediente de frontera de Bertran de Quintana, José, AHG, Fondo del Gobierno Civil de Gerona, legajo 170-478, exp. 372 
menterios clandestinos, cargo que ejerció en Gerona y luego el de Magistrado del Trabajo de la Generalidad. Huyó al extranjero el día 24 de enero de 1939.

Según el Tribunal, Bertran había incurrido en los artículos b, c, d, e y n del artículo $4^{\circ}$ de la ley de 9 de Febrero de 1939 y, en consecuencia, se declaraba la responsabilidad política del inculpado «a quien se le impone la multa de cinco mil pesetas, inhabilitación para cargos políticos y sindicales por quince años y confinamiento en Soria por igual tiempo». A pesar de que no fue una de las penas más duras impuestas por el citado Tribunal ${ }^{81}$ y de que la sanción económica puede considerarse incluso leve, el destierro a Soria tuvo que representar un castigo de peso, pues ¿qué podía hacer Bertran en Soria sin la posibilidad de ejercer como abogado? Al final de su vida, perseguido en España y exiliado en México, el juez Josep Maria Bertran de Quintana, de quien no consta que dejase escritos, fue apagándose y cayendo en el olvido.

\section{BIBLIOGRAFIA}

Aisa Pàmpols, Ferran, Una història de Barcelona. Ateneu Enciclopèdic Popular (1902-1999), Barcelona, Virus Editorial, 2000.

Alquézar, Ramón, L'Ajuntament de Barcelona en el marc del front d'esquerres, Barcelona, Columna, 1986

Álvaro Dueñas, Manuel, «Los militares en la represión política de la posguerra: la jurisdicción de responsabilidades políticas hasta la reforma de 1942», Revista de Estudios Políticos, 69 (Madrid, 1990): 141-162

Bruguera i Cortada, Miquel, «El Tribunal de Depuració de Responsabilitats Polítiques del Col-legi Oficial de Metges de Barcelona», Gimbernat, 50 (Barcelona, 2008): 267-292.

Cambó, Francesc, Meditacions. Dietari (1936-1940), Barcelona, Institut Cambó, 1982

Culla i Clarà, Joan B, El catalanisme d'Esquerra (1928-1936), Curial, Barcelona, 1977.

Digón, Raül, «Joan Comorera i Solé: l'expedient del Tribunal de Responsabilitats Polítiques i el Consell de Guerra», en Cebrián, Carme: Joan Comorera torna a casa, Barcelona, Proa, 2010

Dreyfus-Armand, Geneviève: El exilio de los republicanos españoles en Francia. De la Guerra Civil a la muerte de Franco, Barcelona, Crítica, 2000

Eggers, Christian, «L'internement sous toutes ses formes: approche d'une vue d'ensemble du système d'internement dans la zone de Vichy». [en línea] http://www.memorialdelashoah.org/upload/medias/fr/A1_seltextes_153_eggers.p df (consultado el 10 de septiembre de 2011).

81 Véanse diversos ejemplos en VILANOVA, 1995: 19-36; SANLLORENTE, 2005 o BRUGUERA i CORTADA, 2008: 267-292. 
Fontana Tarrats, José María, Los catalanes en la guerra de España, Madrid, Grafite Ediciones, 2005

García Fontanet, Àngel, «Un aspecte de la repressió franquista de postguerra: La Llei de Responsabilitats Polítiques», en AAVV, Les ruptures de l'any 1939. Barcelona: Publicacions de l'Abadia de Montserrat, 2000

Ivern i Salvà, Maria Dolors, Esquerra Republicana de Catalunya (1931-1936) 2 vol. Barcelona, Publicacions de l'Abadia de Montserrat, 1988.

Juliá Díaz, Santos, Víctimas de la Guerra Civil, Madrid, Temas de Hoy, 2006.

Mateos, Abdón, La batalla de México. El final de la Guerra Civil y la ayuda a los refugiados, Madrid, Alianza, 2009.

Mir, Conxita; Corratgé, Fabià; Farré, Judit; Sagués, Joan, Repressió econòmica i franquisme: l'actuació del Tribunal de Responsabilitats Polítiques a la província de Lleida. Barcelona, Publicacions de l'Abadia de Montserrat, 1997.

Moles, Isidre (ed.), Diccionari dels Partits Politics de Catalunya. Segle XX, Barcelona, Enciclopedia Catalana, 2000.

Sánchez i Farré, Pere, La logia Lealtad. Un exemple de maçoneria catalana (18691939), Barcelona, Alta Fulla, 1985.

Sánchez i Farré, Pere, La maçoneria en la societat catalana del segle XX, Barcelona, Edicions 62, 1993.

Sanllorente, Francisco, La persecución económica de los derrotados. El tribunal de responsabilidades políticas de Baleares (1939-1942), Palma de Mallorca, Marcial Pons, 2005.

Solé i Sabaté, Josep M, Villarroya i Font, Joan, La repressió a la reraguarda de Catalunya (1936-1939), Barcelona, Publicacions de l'Abadia de Montserrat, 1989.

Vázquez Osuna, Federico, La rebel-lió dels Tribunals: l'Administració de justícia a Catalunya 1931-1953: la judicatura i el ministeri fiscal. Catarroja-Barcelona,Ed. Afers, 2005.

Vinanova i Vila-Abadal, Francesc, Repressió econòmica i coacció econòmica. Les responsabilitats polítiques a republicans $i$ conservadors catalans a la postguerra (1939-1942), Barcelona, Publicacions de l'Abadia de Montserrat, 1999.

Vilanova, Francesc, «Les responsabilitats polítiques dels regionalistes catalans (1939-1942)», Recerques, 31 (Barcelona 1995): 19-36.

Vinyes i Roig, Pau, Visca la República! Joaquim Ventalló, periodista, polític, poeta $i$ traducto, Barcelona, Fundació Josep Irla, 2010.

Recibido: 01/03/2012

Aceptado: 03/12/2012 